\title{
The impact of water quality on species diversity and richness of macroinvertebrates in small water bodies in Lake Victoria Basin, Kenya
}

\author{
Steve Omari Ngodhe*, Phillip Okoth Raburu, Boaz Kaunda-Arara and Alfred Achieng \\ University of Eldoret P.O BOX 1125, Eldoret, Kenya.
}

Accepted 2 December, 2013

\begin{abstract}
This study was carried out in small water bodies (SWBs) within Uasin-Gishu and Siaya Counties of Kenya to investigate the effects of water quality on species diversity and richness of macroinvertebrates in these areas. The water quality of the SWBs was assessed in two dams in UasinGishu County (Kesses and Kerita) and the other two in Siaya County (Mauna and Yenga) within Lake Victoria Basin. Water samples for total phosphorus (TP) and total nitrogen (TN) were collected at each sampling station and analyzed using standard methods and procedures. Physico-chemical parameters such as dissolved oxygen (DO), $\mathrm{pH}$ and temperature were taken in situ using electronic meters while biological oxygen demand (BOD) was analyzed using Winkler method after 5-days incubation period. Macroinvertebrate samples were collected using a scoop net (500 $\mu \mathrm{m}$ mesh size) then transferred into a white tray for washing and sorting prior to identification. Preliminary tests of water quality parameters were evaluated by GLM analysis of variance of which very significant differences were observed for both spatial $(p=0.004)$ and temporal $(p=0.001)$ variability with the measured water quality parameters. The results showed that there is both negative and positive change of macroinvertebrate composition and abundance between SWBs over time due to spatio-temporal variation of water quality parameters. Principle Component Analysis (PCA) further confirms this. PCA described over $90 \%$ of variation at the stations. For both seasons, TN, TP, temperature, $\mathrm{pH}, \mathrm{DO}$ and BOD were found to have a significant influence of the species diversity, dominance and richness of macroinvertebrates. Principle component analysis of TN, TP, DO, $\mathrm{pH}$ and BOD for the SWBs described $96 \%$ of their variation when they were compared at temporal and spatial scales. This trend leads to the variation in species diversity; dominance and richness of macroinvertebrates in these SWBs. Water quality and littoral invertebrate mean relative abundance were significantly different among the studied small water bodies during the study period. Overall, water quality seemed to have had effect on species diversity, dominance and richness of the invertebrate benthic community therefore can be used as a bio-monitor to aquatic health.
\end{abstract}

Key words: Water quality, macroinvertebrates, species diversity and richness, small water bodies, Lake Victoria basin.

\section{INTRODUCTION}

Eutrophication due to poor water quality has been the most challenging global threat to the quality of our lakes as a result of excess nutrients getting their way through run off during rainy seasons (Likens, 2010). This process 
of enrichment with excess nutrients, primarily phosphorus and nitrogen, leads to enhanced growth of algae, periphyton and/or macrophytes, as well as increased biological productivity and decreased basin volume from the excessive addition of dissolved and particulate inorganic and organic materials to lakes and reservoirs (Cooke et al., 2005; Likens, 2010). Small water bodies in particular, which are primarily constructed for flood control and irrigation, are experiencing rapid eutrophication due to nutrient loading, sedimentation, acidification, and the introduction of toxic contaminants as a result of runoff water, within Lake Victoria basin lie watersheds dominated by agricultural production, which increases phosphorus-bound sediments in a reservoir, due in part to erosion.

Pollution of these aquatic environments is a significant global water quality management concern. Activities such as agriculture, silviculture, mining and urbanization produce contaminated runoff and excessive sediment that disturb physical habitat (Barbour et al., 1996). These activities combined with highly erodible soils and locally intense rainfall events create high potential for nonpoint source pollution in water bodies (U.S. Department of Agriculture, 1997). The amounts of nutrients in water also play a significant role in influencing the chemistry of aquatic ecosystems. As water flows over rocks and soils, itcarries some nutrients in solution while others are adsorbed into sediments on their way (White et al., 2008). The most important nutrients are those that are often in short supply and those that limit primary species diversity of phytoplankton and macroinvertebrates, like phosphorus, nitrogen or both (Kalff, 2002).

The structure and function of aquatic organisms reflect physical/chemical conditions, and change with increased human influence (Karlson et al., 2002; Herrmann, 1999). For example, in most ecosystems they appear to be controlled mainly by temperature regimes, substratum types and hydraulic variables (Vannote et al., 1980). In contrast, the macroinvertebrate communities of aquatic environments, particularly those in areas of variable climate, may be controlled more by stochastic processes of recruitment, dispersal, colonisation and local extinction, both of the macroinvertebrates themselves and of the macrophyte beds that provide much of their habitat (Batzer and Wissinger, 1996).

In addition, the main physico-chemical factors that affect aquatic environments are temperature, discharge, $\mathrm{DO}, \mathrm{pH}$, nutrients and specific conductivity (Hanninen et al., 2000; Boney, 1989). Temperature is an ecologically significant parameter that is known to influence the structure of aquatic communities (Giller and Malmsqvist, 1998). For example, through combined influences on dissolved oxygen and metabolic activity, temperature has critical effects on species' distributions (Rostgaard and Jacobsen, 2005) and density (Hogg and Williams, 1996). Temperature and dissolved oxygen levels usually fluctuate seasonally and aid in the structuring of benthic communities, which varies from species to species (Shieh and Yang, 2000). It also regulates the amount of dissolved oxygen in water (Kalff, 2002). Increase in temperature lowers its solubility resulting in low values.

Natural differences in $\mathrm{pH}$ and alkalinity may be important determinants of macroinvertebrate community structure in SWBs. Highly acidic water generally results in impoverishment of fauna, and low acidities reflect better buffering and higher productivity (Busulwa and Bailey, 2004). Dam acidification can alter community structure by being acutely or chronically damaging tissues of invertebrates particularly for species that easily loose sodium ions when $\mathrm{pH}$ is reduced (Shieh and Yang, 2000). Secondly, it alters algal communities, upon which some invertebrates depend for food and shelter, altering predation on invertebrates by decimating numbers of other crustaceans, fish, and amphibians, and by altering the bioavailability of some other potential stressors, such as heavy metals. Such effects may reduce invertebrate species diversity, increase the abundance of tolerant species and changed community composition (Shieh and Yang, 2000).

Aquatic macroinvertebrates have the ability to live under different levels of physico-chemical water conditions, and to occupy different substrata. In lowland areas high values of dissolved oxygen can be maintained by minimal interference from anthropogenic activities and the contribution by epilithic algae during photosynthesis.

Benthic macroinvertebrates are used largely in assessments of streams and rivers (Giller and Malmsqvist, 1998); but studies focused on macroinvertebrates as indicators in lakes and reservoirs are less common. Few studies (Griffith et al., 2005; Batzer and Wissinger, 1996) have been conducted to determine how communities within a water body respond to the changes in water quality, specifically macroinvertebrates in small water bodies. By comparing spatial and temporal data it can be determined if the macroinvertebrate community has been reset to its original composition and the impact of the water quality on the community. The objective of this paper was to determine any changes in the benthic macroinvertebrate community in response to change in water quality in small water bodies within Lake Victoria basin, Kenya during the study period.

\section{MATERIALS AND METHODS}

\section{Study area}

The study was carried out in SWBs within the Lake Victoria Basin which was stratified in terms of altitude difference, their sizes and continuous availability of water. The low altitude sites were represented by Yenga and Mauna Dams in Siaya county and high altitude by Kesses and Kerita Dams in Uasin-Gishu County (Figure 1).

Kesses dam is located at latitude and longitude of $00^{\circ} 17.263^{\prime} \mathrm{N}$, and $035^{\circ} 19.852^{\prime} \mathrm{E}$, respectively (GPS readings, etrex Garmin model). The littoral zone was dominated by Typha latifolia and Cyperus papyrus species. In the shallow littoral areas, water lilies, Nyphae lotus, water fern, Azolla spp., water cabbage, Pistia stratoites, Salvinia, Lemna, Ceratophylum dermersum, Potamogeton, Ultricularia and Najas species are found. The dam is drained by 


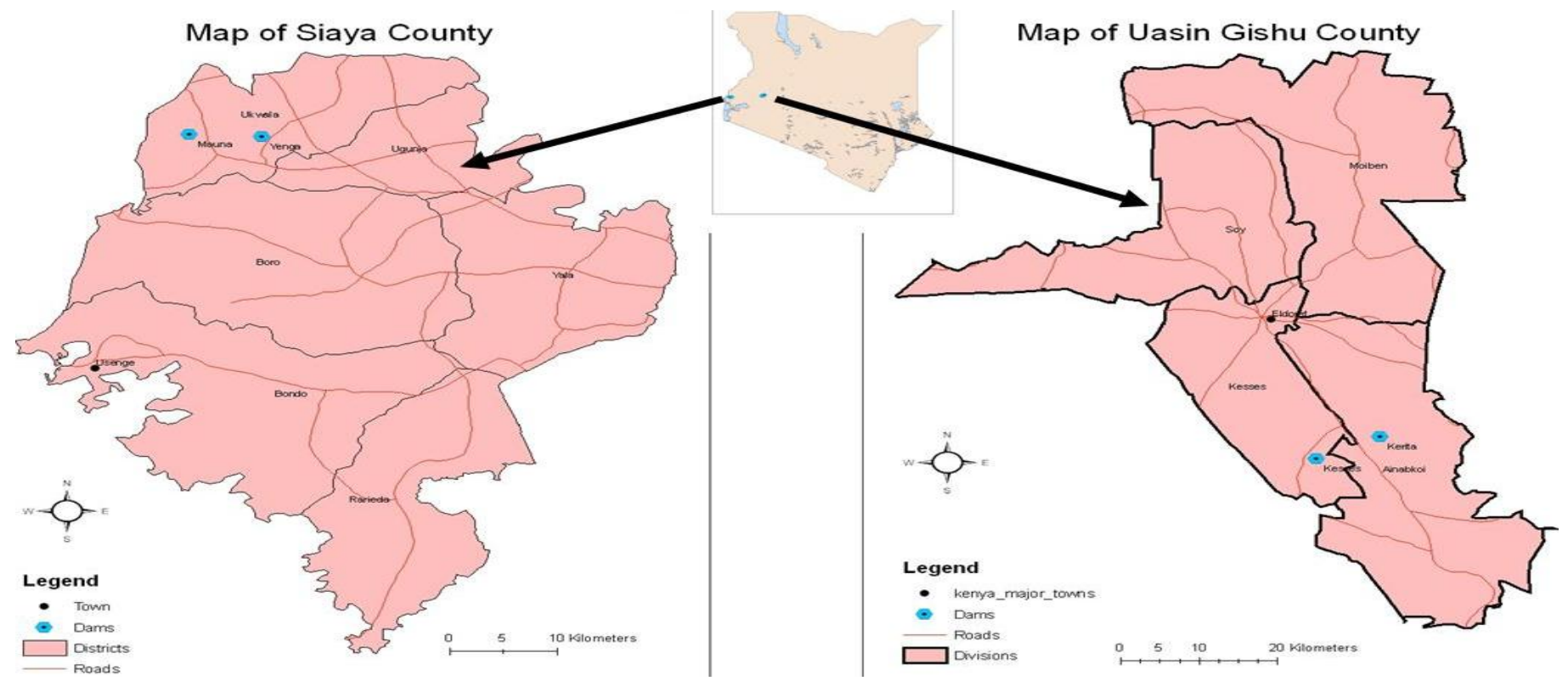

Figure 1. Location of Siaya and Uasin-Gishu counties with demarcations of small water bodies (Source: author).

two rivers from the east including Endaragwa and Endaragweta. It has a surface area of approximately 500 acres and a maximum depth of $4.48 \mathrm{~m}$ while Kerita lies at latitude and longitude of $00^{\circ} 19$. $263^{\prime} \mathrm{N}$, and $035^{\circ} 24.329^{\prime} \mathrm{E}$, respectively (GPS readings, etrex Garmin model). The most noticeable emergent macrophytes in the littoral zone was dominated by $T$. latifolia and $C$. papyrus. It is also fed by two rivers, that is, River Chebolol entering in the south-east direction and Kabiyemit which enters the dam in the south-west direction. It has a surface area of approximately 25 acres and a maximum depth of $3 \mathrm{~m}$ (Ngodhe et al., 2013).

Yenga is located at latitude and longitude $00^{\circ} 13^{\prime} 03^{\prime \prime} \mathrm{N} ; 034^{0} 12$ $44^{\prime \prime} \mathrm{E}$, respectively. It has steep sided edges. The littoral zones are composed of sandy and rocky bottoms with loose macrophytic detrital and animal manure deposits brought in by surface runoff from the catchment characterize the littoral zones. The dam is dendritic in shape, has a seasonal feeder stream called Ugege and a permanent spillway. It has a surface area of approximately 15 acres and a maximum depth of $4.5 \mathrm{~m}$. Mauna is situated at latitude and longitude of $00^{\circ} 12^{\prime} 358^{\prime \prime} \mathrm{N} ; 034^{\circ} 09^{\prime} 433^{\prime \prime} \mathrm{E}$, respectively. It has steep sided edges. The littoral zones are composed of sandy and rocky bottoms with emergent macrophytes such as Typha sp., papyrus sp., reeds and sedges dominated the zone. It has a surface area of approximately 35 acres and a maximum depth of $4 \mathrm{~m}$ (Ngodhe et al., 2013). Sampling was undertaken in each dam at monthly intervals from December 2010 till June 2011 on various sampling sites (Figure 2)

\section{Water quality}

Triplicate samples were collected at $10 \mathrm{~cm}$ below the water surface in each dam monthly at the chosen sampling sites (Figure 2). The physico-chemical parameters in the different microhabitats were measured in situ, temperature and $\mathrm{pH}$ were measured by a combined $\mathrm{pH}$-and-temperature-meter $\left(\mathrm{OAKTON}^{\mathrm{R}}\right.$, Model $\mathrm{pH} / \mathrm{Mv} /{ }^{\circ} \mathrm{C}$ METER, Singapore). Two sets of triplicate water samples were collected in glass stoppered bottles at each sampling station for dissolved oxygen (DO) and biological oxygen demand (BOD) using Winkler's method (APHA, 1998). The first set used to determine DO was fixed using $2 \mathrm{ml}$ manganous sulphate followed by $2 \mathrm{ml}$ of Winkler's reagent.
Samples for determination of total phosphorus (TP) and total nitrogen (TN)) were collected using plastic sampling bottles of 500 $\mathrm{ml}$. The samples were fixed with 3 drops of concentrated sulphuric acid in the field and transported in a cool-box to maintain the nitrogen balance to the laboratory for further analyses. Total nitrogen was determined using the Kjeldahl method in the laboratory (APHA, 2000). A $50 \mathrm{ml}$ water sample was taken in a conical flask to which $2 \mathrm{ml}$ of ammonium chloride solution was added. The solution was then mixed well. The first $10 \mathrm{ml}$ of the sample was run through the cadmium column and discarded, and the following $25 \mathrm{ml}$ of solution was collected in a conical flask to which $0.5 \mathrm{ml}$ of sulphanilamide solution was added. After about $5 \mathrm{~min}, 0.5 \mathrm{ml}$ of $\mathrm{n}-1$ naphthyl- ethylene diamine dihydrochloride was added and the solution was mixed well. After $1.5 \mathrm{~h}$, the absorbance of the solution was measured at a wavelength of $543 \mathrm{~nm}$ in a Spectrophotometer (Pharmacia Biotech model, 65455). A $50 \mathrm{ml}$ of distilled water and different standard solution were also treated as above. Total nitrogen was calculated using the formula:

$\mathrm{TN}$ in $\mathrm{mg} / \mathrm{L}=\mathrm{F}\left(\mathrm{E}_{1}\right.$ sample $-\left(\mathrm{E}_{0}+\mathrm{E}_{\mathrm{B} 1}\right)$

Where

Sample concentration (of $\mathrm{NO}_{3}-\mathrm{N} / 1$ in $\mathrm{mg} / \mathrm{L}$ )

$F=\overline{E_{1}-E_{B 1}}$

$\mathrm{E}_{0}=$ absorbance of sample without reductant; $\mathrm{E}_{\mathrm{B} 1}=$ absorbance of distilled water + reagent; $E_{1}=$ absorbance of sample with reagent Total phosphorus was measured using the persulfate digestion method (APHA, 2000). A $100 \mathrm{ml}$ of mixed reagent was added to a flask with $100 \mathrm{ml}$ of sample. Simultaneously, $10 \mathrm{ml}$ of mixed reagent without reductant was added to another flask with $100 \mathrm{ml}$ of sample and the sample thoroughly mixed. After $1.5 \mathrm{~h}$, extinction coefficient of the solution was measured at a wavelength of $885 \mathrm{~nm}$ in a spectrophotometer (Pharmacia Biotech model, 65455). The absorbance of the reagent and distilled water blank was also measured. The total phosphorus content of the sample was calculated as follows: 




Figure 2. A sketch of the small water bodies showing the sampling sites (KES $1=$ Kesses station 1 , KES $2=\mathrm{Kesses}$ station 2 , KES $3=$ Kesses station 3, KES $4=$ Kesses station 4, KES $5=$ Kesses station 5, KES $6=$ Kesses station 6, KES OW = Kesses open waters, KER 1 $=$ Kerita station 1, KER $2=$ Kerita station 2, KER $3=$ Kerita station 3, YEN 1 = Yenga station 1, YEN $2=$ Yenga station 2 , YEN $3=$ Yenga station 3, MAU 1 = Mauna station 1, MAU 2 = Mauna station 2 and MAU 3 = Mauna station 3).

$\mathrm{TP}$ in $\mu \mathrm{g} / \mathrm{L}=\mathrm{F}\left(\mathrm{E}_{1}\right.$ sample $-\left(\mathrm{E}_{0}+\mathrm{E}_{\mathrm{B} 1}\right)$

where:

Sample concentration (of $\mathrm{PO}_{4}-\mathrm{P} / \mathrm{l}$ in $\mu \mathrm{g} / \mathrm{L}$ )

$\mathrm{F}=$

$$
E_{1}-E_{B 1}
$$

$E_{0}=$ absorbance of sample without reductant; $E_{1}=$ absorbance of sample with reductant; $\mathrm{E}_{\mathrm{B} 1}=$ absorbance of distilled water + reagent.

\section{Macro invertebrates}

Littoral macroinvertebrates were sampled using a scoop-net of 0.5 $\mathrm{mm}$ mesh size with $0.4 \mathrm{~m}$ diameter. The samples were sorted live in a white plastic tray and placed into vials and preserved with $70 \%$ ethanol. The samples were then transported to the laboratory for further sorting, counting and identified to genus level using identification keys (Merritt and Cummins, 1997; IFM, 2006).

\section{Data analysis}

The mean, standard errors, line-graphs and bar graphs (classical analysis methods) were carried out to see the variation trend. Species richness, diversity (Simpson's) and dominance were calculated for comparison and prior analysis of any uniqueness or difference in the sampled biological community at different pollution gradient (Microsoft excel 2013 and Minitab 16). The diversity indices (Simpson diversity index and Dominance of the taxa at the sampled stations) were then computed for macro invertebrates using PAST statistical software. General linear model analysis of variance was also undertaken for the six water quality parameter mean measurements (temperature, DO, BOD, TN, TP and $\mathrm{pH}$ ) to determine if there is any significant difference in these measurements among the stations, between the months, if there is any interaction between stations and the months sampled (using Minitab 16 software). Further analysis of the above six water quality parameters related to the stations was done with multivariate method using PAST Software. Principle component analysis of the Stations and six mean water quality parameters (temperature, DO, $\mathrm{BOD}, \mathrm{TN}, \mathrm{TP}$ and $\mathrm{pH}$ ) measurements were evaluated for the variation of the stations with these measurements.

\section{RESULTS}

\section{Water quality}

The mean monthly values of physico-chemical parameters and nutrients recorded among the dams during this study are summarized in Figures 3 to 8 . Mean pH change fluctuated at the four dams and at different months. Kesses dam reached its peak during January2011 and April 2011 but low values were recorded during December 2010 and June 2011. In Kerita Dam, the highest value was registered during the months of March and April 2011 with small variation during other months. Yenga Dam also fluctuates during the sampling periods with the peak during January 2011 and the same trend was also seen in Mauna Dam with the highest value registered during November 2010 and lowest in April and May 2011. All dams registered a pH value of above 7 in all months sampled.

Figure 4 shows the temperature variation during the 


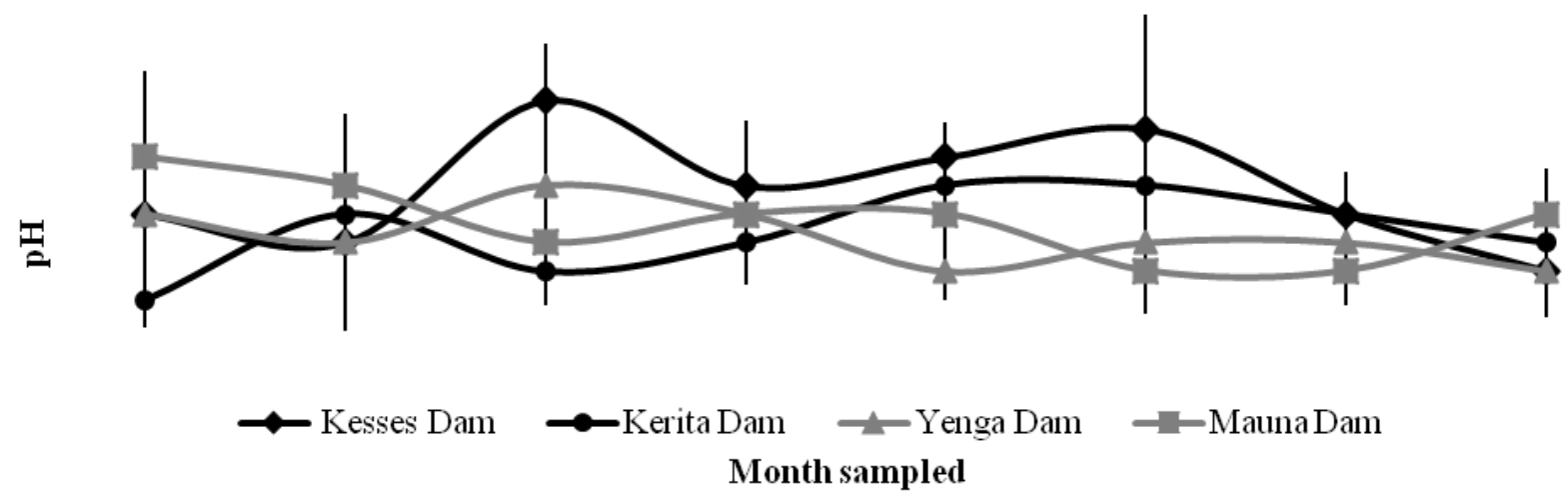

Figure 3. Mean \pm SE monthly $\mathrm{pH}$ values in small water bodies during the study period.

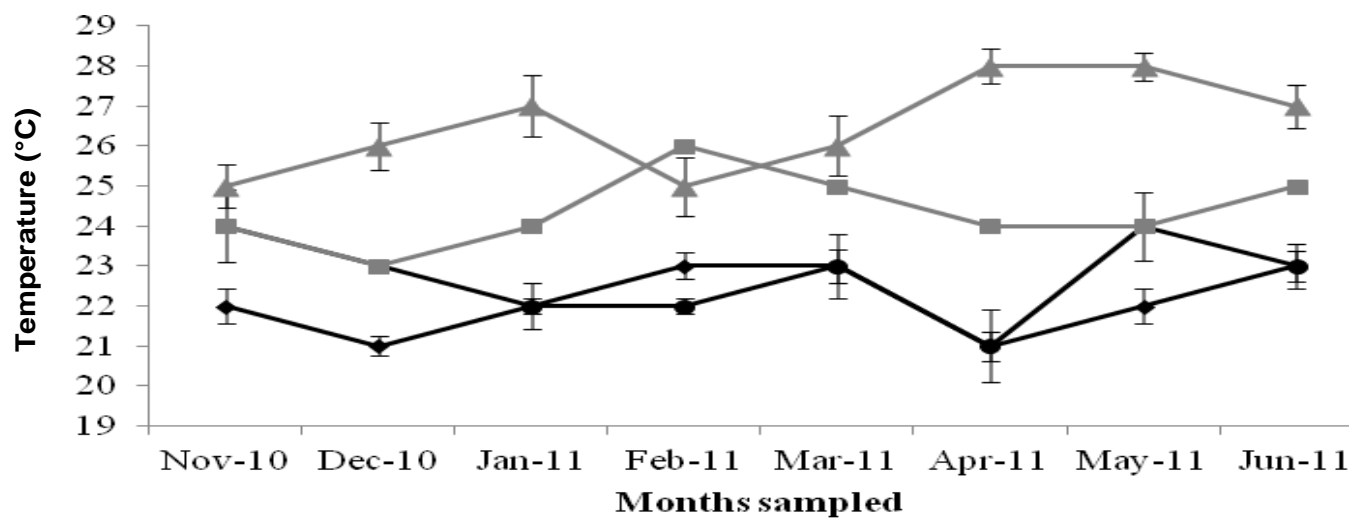

$\longrightarrow$ Kesses Dam $\longrightarrow$ Kerita Dam $\longrightarrow$ Yenga Dam $\longrightarrow$ Mauna Dam

Figure 4. Mean \pm SE monthly temperature values in small water bodies during the study period.

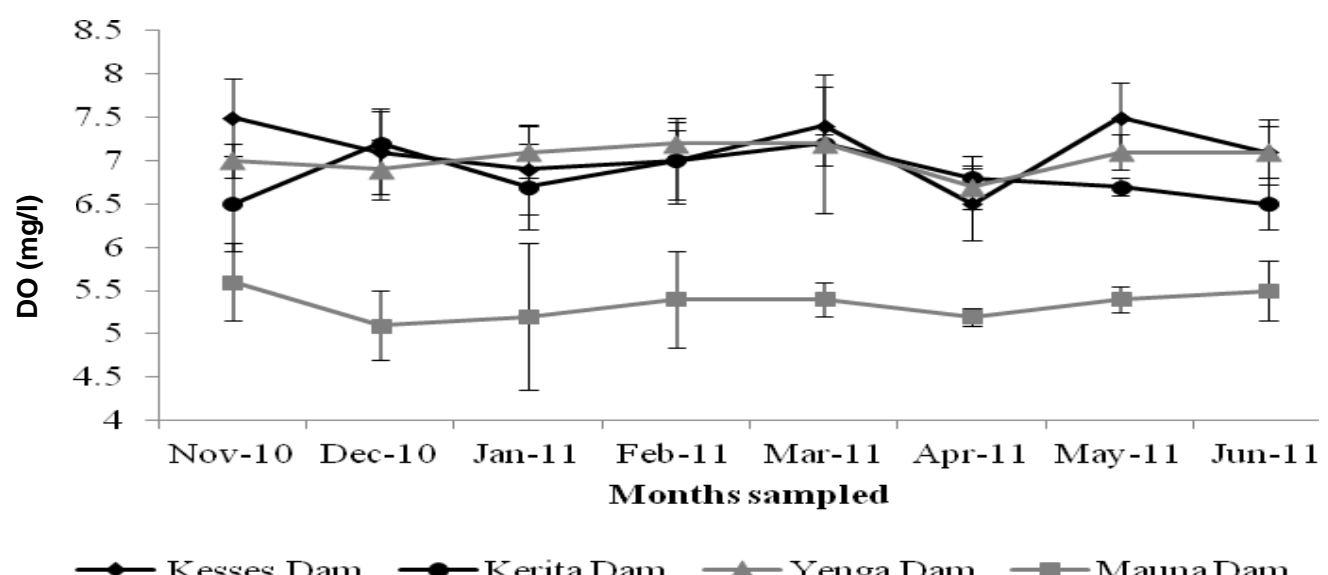

Figure 5. Mean \pm SE monthly DO values in small water bodies during the study period.

study period. The temperature values were high in the low altitude dams (Yenga and Mauna). The temperature values were recorded during the last three months (April, May and June 2011) in Yenga Dam while it was highest and lowest during the months of February 2011 and December 2010, respectively, in Mauna dam. In the high altitude dams (Kesses and Kerita), there was no clear trend with high values recorded during November 2010 


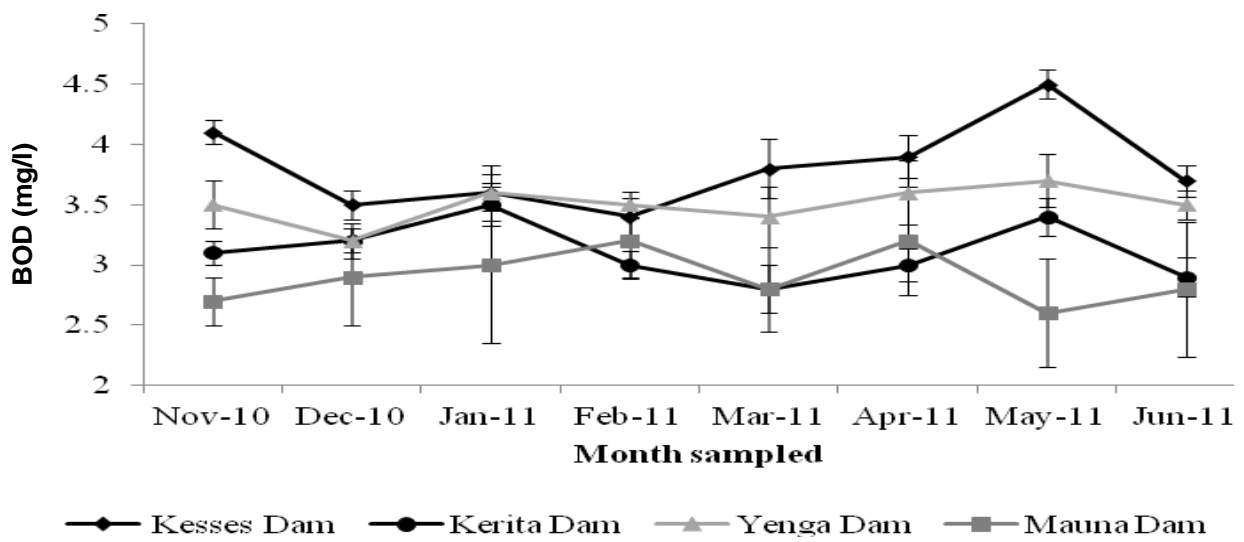

Figure 6. Mean \pm SE monthly BOD values in small water bodies during the study period.

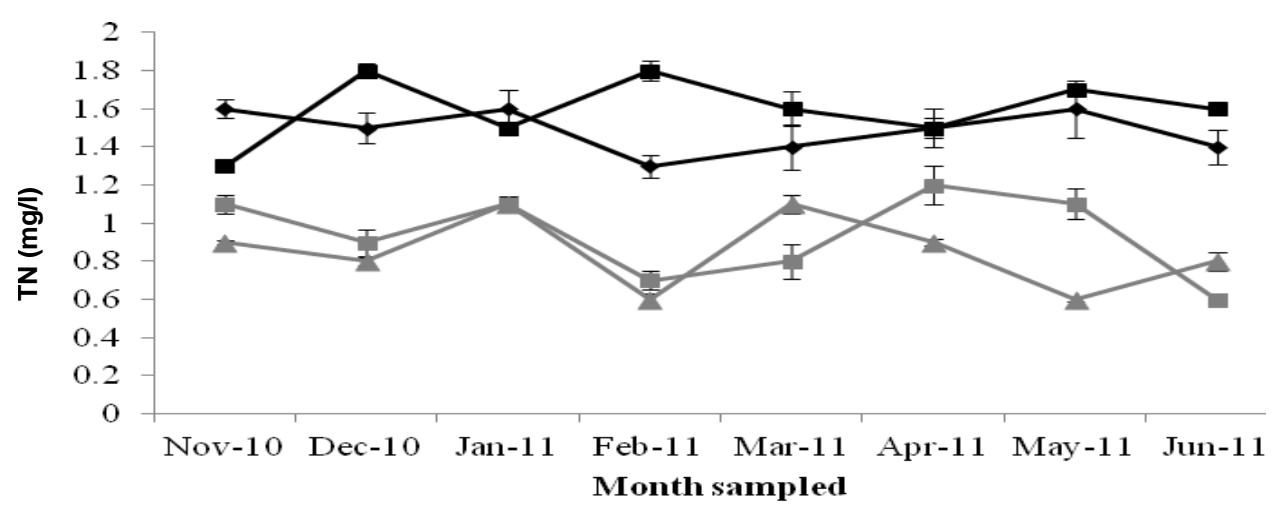

$\longrightarrow$ Kesses Dam $\rightarrow$ Kerita Dam $\rightarrow$ Yenga Dam $\rightarrow$ Mauna Dam

Figure 7. Mean \pm SE monthly total nitrogen $(T N)$ values in small water bodies during the study period.

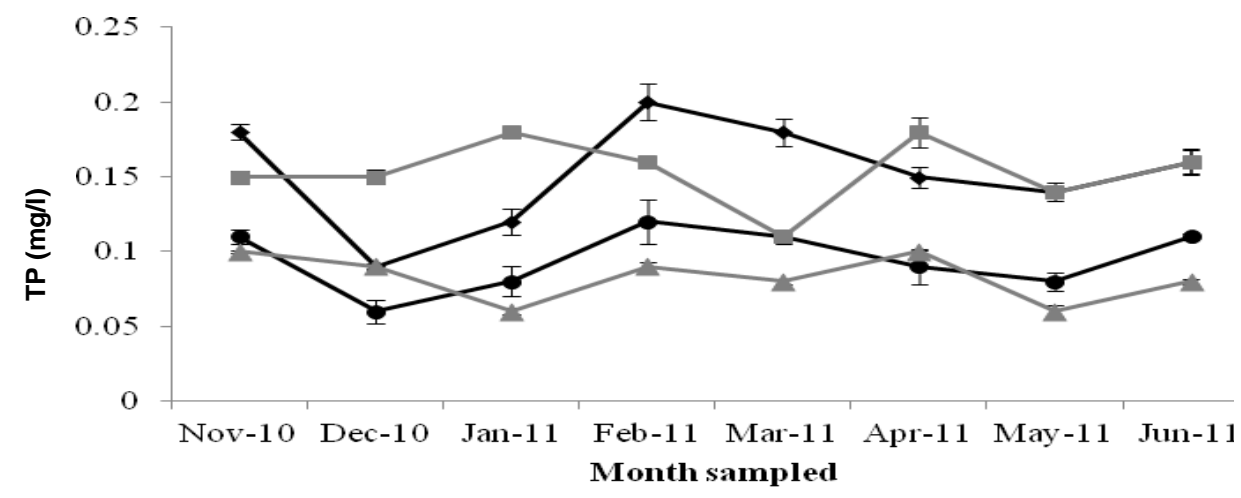

$\multimap$ Kesses Dam $\multimap$ Kerita Dam $\multimap$ Yenga Dam $\longrightarrow$ Mauna Dam

Figure 8. Mean $\pm S E$ monthly total phosphorus (TP) values in small water bodies during the study period.

and May 2011 in Kerita while in Kesses the highest was registered during the months of March and June 2011.

Mean DO change also revealed a similar trend in all dams and at different months. Kesses Dam had November 2010, March and May 2011. There was a similar trend in Kerita and Yenga with slight differences in values recorded 


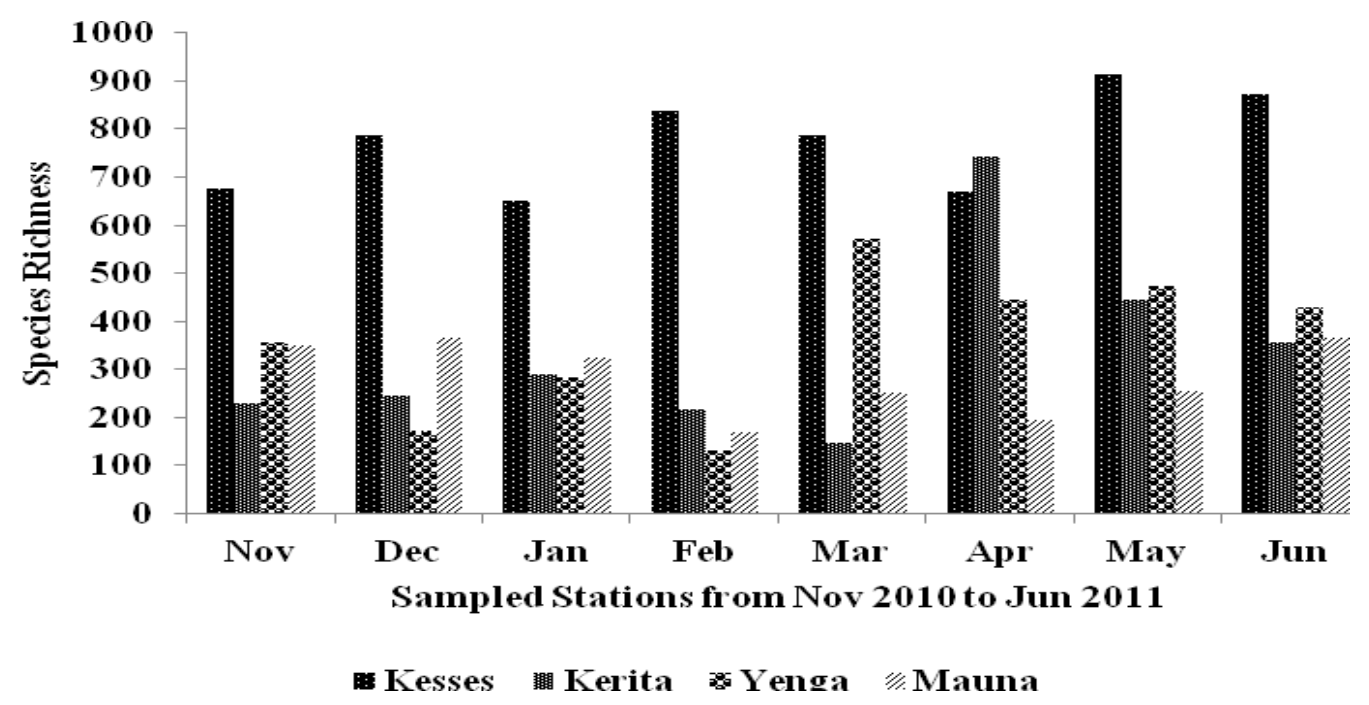

Figure 9. Species richness in small water bodies during the study period.

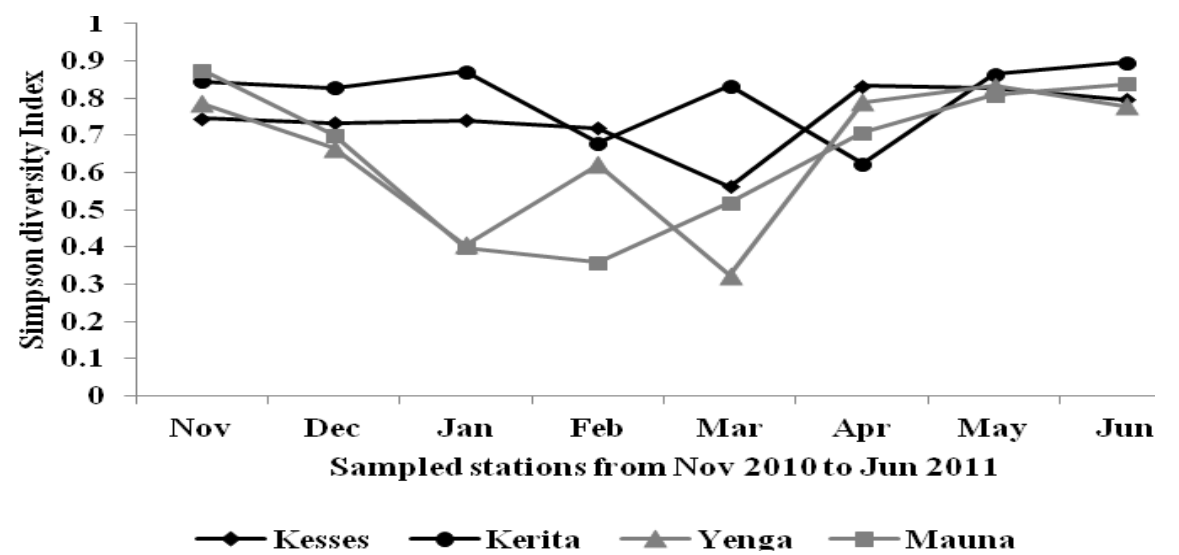

Figure 10. Simpson's diversity index of the macro invertebrates in SWBs during the sampling period.

in all months sampled. Mauna Dam was different from other three dams. It registered the lowest DO values throughout the study period with its highest recorded during the month of January 2010 with almost the same value during the other months (Figure 5).

Biological oxygen demand (BOD) values are shown in Figure 6. Kesses and Yenga dams registered the highest values, Kesses and Yenga reached their peak during the month of May 2011 while their lowest values were recorded during the months of December 2010 and February 2011. On the other hand, Kerita Dam had intermediate values with the highest value registered during the months of January 2011 and May 2011 while Mauna dam had the lowest BOD in all the studied months except during the month of February and April 2011 where the value was above what was seen in Kerita Dam. Both Mauna and Kerita registered the sam value of $B O D$ during the month of March 2011 (Figure 6).

Total nitrogen (TN) was high in high altitude dams in all months samples, the highest values was recorded in Kerita during the months of December 2010 and February 2011 while the low altitude dams registered moderately high figures with a similar trend observed between the two dams (Yenga and Mauna) with their values being slightly above and below 1 (Figure 7). Total phosphorus (TP) did not follow the same trend as the values were highest in Kesses and Mauna dams unlike the other two dams where the values were low with a similar trend with Yenga having the lowest during the months of January and May 2011 (Figure 8).

The species richness in small water bodies during the study period is shown in Figure 9. Kesses Dam generally recorded the highest values with its peak reached during the month of May 2011. The richness was higher in Kesses than in all other small water bodies during the study period except during the month of April 2011 where Kerita Dam had the highest richness (Figure 9). The other dams did not vary much in terms of species richness 


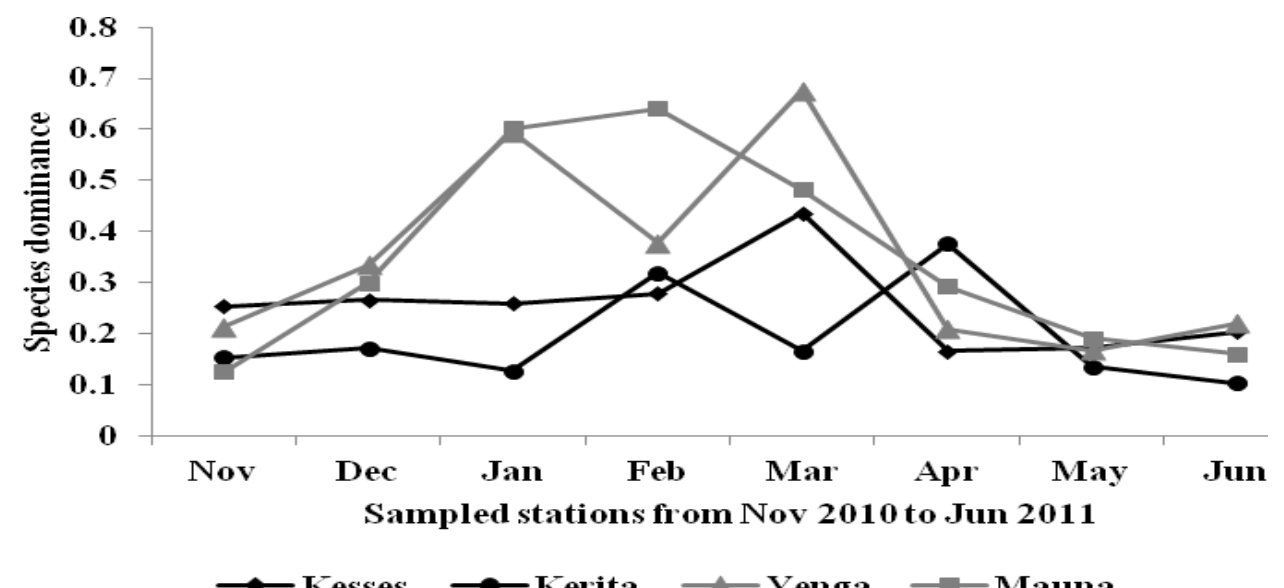

Figure 11. Species Dominance of the macro invertebrates in SWBs during the sampling period.

except during the month of March 2011 where Yenga dam was much higher than Kerita and Mauna (Figure 9).

Simpson's diversity Index and dominance is shown in Figures 10 and 11. In general, all small water bodies had moderately high diversity indices in all months sampled except during the months of January, February and March 2011 where the diversity was low in Yenga and Mauna Dams (Figure 10). Dominance was high in Yenga and Mauna dams where there was up and down movement. There was low dominance in Kesses and Kerita as compared to other two dams though the values were constantly fluctuating throughout the study period with Kerita Dam recording the lowest of all in most months (Figure 11). General linear model revealed there was significant spatio-temporal difference in species diversity during the study period ( $p=0.004$ and $p=0.001$ ) respectively.

The mean physico-chemical water quality parameter measurements were also compared during the study period as presented in Figure 12. Component 1 described $82.35 \%$ of this variation while component 2 had $14.34 \%$ variance. High TN, TP and $\mathrm{pH}$ influence was shown to be of significance with large Eigen-vector displacement along the horizontal axis and its influence was on Kesses and Kerita Dams. The same could be deduced with DO and BOD (positive coefficient) with component 1 that describes $82.35 \%$ of the variation among the dams; this is negative with respect to Mauna and Yenga Dams. Temperature positively affected Mauna and Yenga yet negatively influenced Kessess and Kerita with component 1. The combination of these two components explains $82.35+14.34=96.69 \%$ of the variation in water quality parameters among the dams (Figure 12).

\section{DISCUSSION}

Water quality parameters such as DO, BOD and nutrients revealed a drastic increase and decrease in their concentrations for all water bodies sampled during the entire study period. This spatio-temporal change of water quality which could be attributed to different concentration of organic matter within a water body at a given point in time influenced the composition and distribution of macro invertebrates. This observation is supported by Peeters et al. (2004) and Orwa et al. (2013) who stated that the distribution and composition of aquatic macroinvertebrate communities are influenced by a variety of environmental factors such as habitat characteristics, water quality, sediment quality, food quality and quantity along with biological factors such as competition and predation. As these environmental and biological factors change over time, the macroinvertebrate community also changes. Physico-chemical parameters such as temperature, $\mathrm{pH}$, $\mathrm{DO}, \mathrm{BOD}$ and TN directly influenced the composition and abundance of macrointervertebrates. High temperature, low TN, low DO and high BOD negatively influenced the species diversity, dominance and richness in Yenga and Mauna Dams as they recorded low species diversity and richness as compared to Kesses and Kerita Dams which had low temperatures, high TN, high DO and low BOD resulting in high species richness. TP and $\mathrm{pH}$ did not show any clear effects on macroinvertebrate diversity and richness. The changes of species diversity and richness were probably due to variation in the tolerance level of environmental degradation due to anthropogenic impacts observed in the dams. This could conform to the physical structure that could have provoked perturbations in aquatic invertebrate communities, but the response to such events varies according to species. This is also supported by Kari and Rauno (1993), Griffith et al. (2005) and Orwa et al. (2013) who concluded that the distribution of aquatic macroinvertebrate occurrence is set by physical and chemical tolerance of the individual macro invertebrates to an array of environmental factors. A lower value of the diversity index is generally interpreted as characteristic of polluted conditions over time, where a few tolerant genera dominate the community while higher values are recorded in unpolluted waters. Low species diversity was observed during high temperatures, low DO and high 


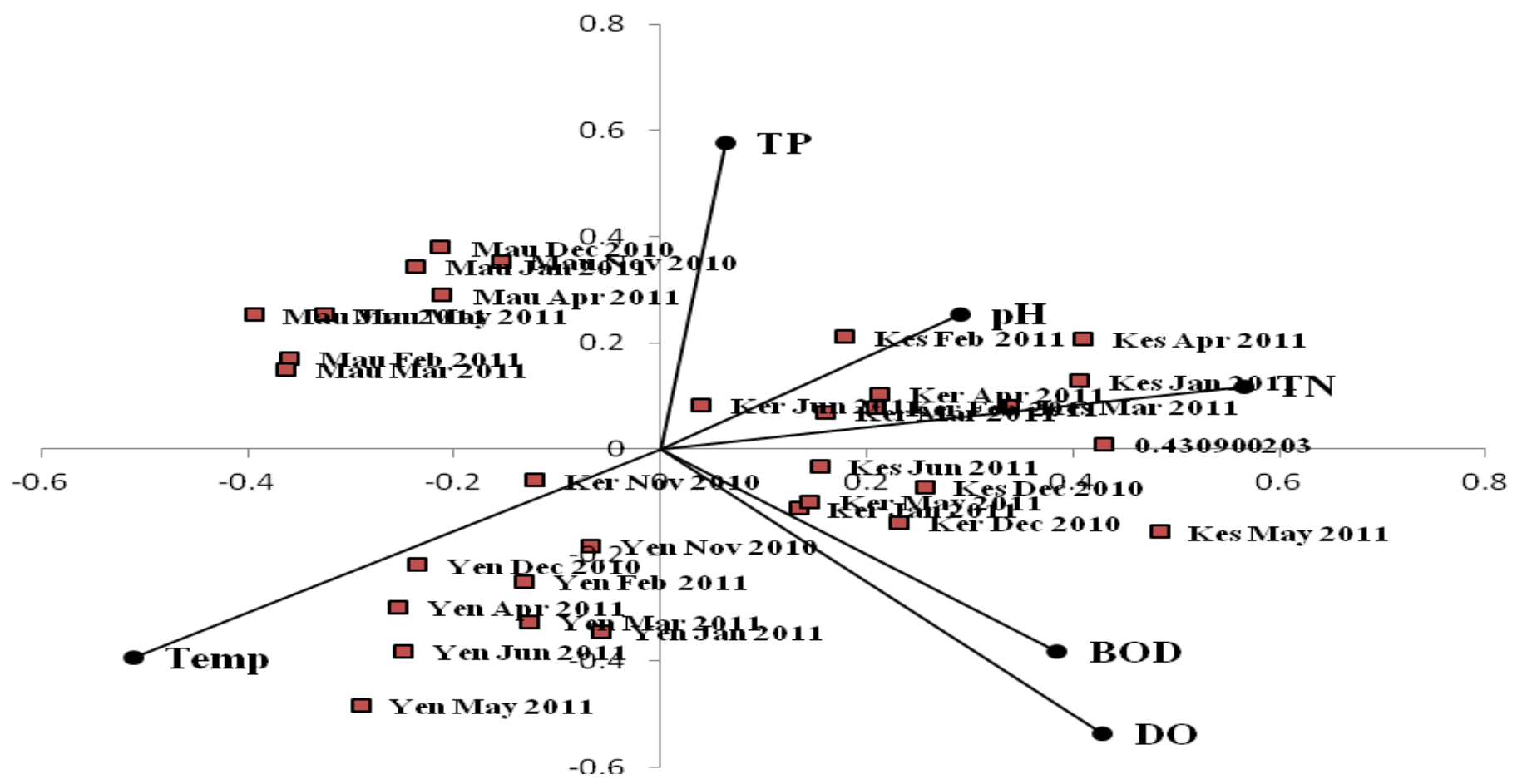

Figure 12. Principle component analysis of the mean water quality parameters during the study period.

BOD in Yenga and Mauna Dams as compared to Kesses and Kerita Dams. This is due to high competition for DO by macro invertebrates during respiration which only make the more tolerant species survive as the temperature conditions might also not be favourable to less tolerant species. This is in line with Seaman and Kok (1987) who reported that dissolved oxygen (DO) concentration in SWBs varied according to local conditions, mainly temperature, time of the day and season. In the present study, higher DO concentrations were recorded in water bodies at lower temperatures (low altitude areas) than in higher temperatures (high altitude areas). A possible explanation for this is that higher temperatures induce increased biological activity in the water column, with larger organisms requiring more $\mathrm{DO}$ for respiration and the smaller microorganisms increasing their demand for DO in order to carry out aerobic biodegradation of deposited organic matter in the water body this results into only more tolerant species thriving as opposed less tolerant ones. This trend was clear in high and low altitude dams as they registered high and low species diversity and richness. It was also observed that higher DO concentrations occurred in sampling months just after heavy down pour and were lowest during dry spell. This phenomenon could be explained by what can be termed the "cascading temperature and standing crop" theory of lentic water bodies according to Seaman and Kok (1987). During the short rains, temperatures are moderate; nutrients enter the water bodies through runoff and streams; due to the favourable temperatures and increased nutrient levels, there is algal bloom resulting into higher algal standing crop with increased DO from the photosynthetic activities of these algae; the high biomass of algae cause the standing crop of macroinvertebrate and zooplankton to increase up to a given tolerant limit; beyond this limit the standing crop of these biological organisms will decrease. The cascading consequences are that during the dry spell the phytoplankton, deplete much of the nutrients while at the same time the macroinvertebrates and large zooplankton population exert increased grazing pressure on the algae, resulting into heightened mortality rates of algae, reduced photosynthetic activity, more demand for DO to support respiratory activity of larger organisms, higher demand for aerobic respiration by microorganisms and therefore, reduced DO and increased biological oxygen demand (BOD) in the water column (Seaman and Kok, 1987; Ngodhe et al., 2013). This could explain the present results as it imply that variation in temperature and DO cause negative or positive growth in macro invertebrates hence high species diversity and richness as was also reported by Sabater (2004).

Principal component analysis (PCA) has been used to differentiate waters of different qualities (Zhang et al., 1992; Brodnjak-voncina et al., 2002) by chemometrics methods used for the classification and comparison of different samples (Massart et al., 1997). Since the vector displacement of the principal components are directly related/proportional to the level/extent of the effect of the variables measured and the stations they correspond to, the largest principle component vector displacement among 
the stations was deduced to be the most polluted area. In this study, PCA further confirmed the change of species diversity, dominance and richness with the change of water quality parameters in different water bodies. Component 1 and 2 are sufficient to describe the environmental factors (water quality parameters) that affect these water bodies for instance, Kesess and Kerita have a strong positive influence of $\mathrm{pH}, \mathrm{TN}, \mathrm{BOD}$ and $\mathrm{DO}$ with component 1 that describes $82.347 \%$ of the variation among the stations, this is negative with respect to Mauna and Yenga Dams. The converse is true for temperature which positively affects Mauna and Yenga yet negatively influence Kesses and Kerita with component 1 while component 2 have 14.34\% variance (Figure 12). The combination of these two components explains $82.347+$ $14.34=96.687 \%$ of the variation in water quality parameters among the small waterbodies. This analysis confirms the impact water quality parameters have on macro invertebrate communities. This concurs with Herrmann (1999) who noted that slight eutrophication due to change in water quality seems to favour increased diversity, however, excess amounts of nutrients resulting in increased primary production and consequently oxygen depletion, probably affecti macroinvertebrate diversity negatively. Harding et al. (1998) also noted similar weak significant correlation results and suggested that high periphyton biomass due to nutrient enrichment and sedimentation in some of the stations that they sampled favoured some taxa such as Chironomids, Snails and Oligochaetes at the expense of Ephemeroptera and Trichoptera. This study noted the decline in diversity of macroinvertebrates, with the low abundance or absence of Ephemeroptera and Trichoptera due to increased nutrient levels because of agricultural and other anthropogenic activities. It can therefore be concluded that variation in species diversity, dominance and richness were as a result of spatio-temporal change of water quality parameters sampled.

\section{ACKNOWLEDGEMENT}

The authors wish to thank National Council of Science and Technology (NCST) for funding this study and also Department of Fisheries and Aquatic Sciences of University of Eldoret for provision of both laboratory space and technical support during the entire study period.

\section{REFERENCES}

APHA (2000) Standard methods for the analysis of water and wastewater, 15th ed. American Public Health Association and Water Pollution Control Federation. Washington DC, USA. p. 44.

APHA (American Public Health Association) (1998). Standard methods for the examination of water and wastewater, $20^{\text {th }}$ edn. APHA, Washington, D.C

Barbour MT, Diamond JM, and Yoder CO (1996) Biological assessment strategies: Applications and Limitations. In: Whole effluent toxicity testing: an evaluation of methods and prediction of receiving system impacts (Grothe, D.R., Dickson, K.L. and Reed-Judkins D.K., eds), SETAC Press, Pensacola. pp. 245-270.

Batzer DP, SA Wissinger (1996) Ecology of insect communities in nontidal wetlands. Ann. Rev. Entomol. 41: 75-100.
Boney AD (1989). Phytoplankton: Great Britain. Chapman and Hall, London. p. 118.

Busulwa HS, Bailey RG (2004) Aspects of the physico-chemical environment of the Rwenzori Rivers, Uganda. Afr. J. Ecol. 42 (1): 8792.

Cooke DG, EB Welch, SA Peterson and SA Nichols (2005). Restoration and management of lakes and reservoirs. Taylor \& Francis, Boca Raton, Florida.

Giller PS, Malmsqvist B (1998) The Biology of Streams and Rivers. Oxford University Press, New York. p. 296.

Griffith MB, Hill B, McCormick H, Kaufmann R, Herlihy T and Selle AR (2005) Comparative application of indices of biotic integrity based on periphyton, macroinvertebrates, and fish to southern Rocky Mountain streams. Ecol. Indic. 5:117- 136.

Harding JS, Benfield EF, Bolstad PV, Helfman GS, Jones EBD (1998). Stream biodiversity: The ghost of land use past. Proc. Natl. Acad. Sci. 95:14843 14847.

Herrmann J (1999) Freshwater biodiversity and Ecosystem functions; ideas and the case River Eman.In: Friberg $\mathrm{N}$ and Carl JD (Eds), Biodiversity in Benthic Ecology. Proc.Nordic Benth Meeting, Silkeborg, Denmark. Tech. Report 266: 11.

IFM (Institute of Fisheries \& Macroinvertebrate Identification) (2006) Aquatic Ecology. Department of Biology, Sweden: Linkoping University Press. p. 21.

Kalff J (2002). Limnology: inland water ecosystems. Prentice Hall Inc. Upper Saddle River,New Jersey. pp.592.

Kari H, Rauno V (1993) Insects and pollution. CRC Press Inc. Florida. p.16.

Likens GE (2010) Lake ecosystem ecology. Academic Press. San Diego, California.

Merritt RW, KW Cummins (1997). An Introduction to Aquatic Insects of North America. $3^{\text {rd }}$ Edition. Kendall/Hunt Publishing Company, Dubuque, lowa, USA. p. 26.

Ngodhe SO, Raburu PO, Matolla GK and Orwa PO (2013). Assessment of Water Quality, Macroinvertebrate Biomass and Primary Productivity of Small Water Bodies for increased Fish Production in the Lake Victoria Basin, Kenya. Lakes and Reservoirs: Res. Mangt. 18: 89-97

Peeters ET, Gylstra MR, Vos HJ (2004). Benthic macroinvertebrate community structure in relation to food and environmental variables. Hydrobiologia 519:103-115.

Rostgaard S, Jacobsen D (2005). Respiration rate of stream insects measured in situ along a large altitude range. Hydrobiologia 549: 79-98.

Sabater S (2004) Diatom communities as indicators of environmental stress in the Gaudiamar river, S-W. Spain, following a major mine tailing spill. J. Appl. Phycol. 12:113-124.

Seaman MT, Kok DJ (1987) Ecological diversity in Orange Free State pans. Occasional Report series No. 28. Ecosystem Programmes Foundation for Research and Development. CSIR. Pretoria: 260-273

Shieh SA, Yang PS (2000). Community structure and functional organization of aquatic insects in an agricultural mountain of Taiwan. Zool. Stud. 39:191-202.

US Department of Agriculture (1997). Choctawhatchee and Pea River Basin Study, Alabama and Florida Reconnaissance Report. Water Resources Planning Staff Auburn, Alabama, Gainesville, Florida.

Vannote RL, Minshall GW, Cummins KW, Sedell JR, Cushing CE (1980) The River continuum concept. Can. J. Fish. Aquat. Sci. 37: 130-137.

White MS, Xenopoulo MA, Hogsden K, Metcalfe RA, Dillon PJ (2008) Natural lake-level fluctuation and associated concordance with water quality and aquatic communities within small lakes of the Laurentian Great Lakes region. Hydrobiologia 613:21-31. 